Indonesian Journal of Global Health Research

Volume 3 Number 3, August 2021, pp. 281 - 288

e-ISSN 2715-1972; p-ISSN 2714-9749

http://jurnal.globalhealthsciencegroup.com/index.php/IJGHR

\title{
THE IMPACT OF THE COVID-19 PANDEMIC ON CHILDREN AND ADOLESCENTS MENTAL HEALTH: A LITERATURE REVIEW
}

\author{
Dipa Ghosh \\ Government School of Nursing, Ghatal, Department of Health and Family Welfare, GN-29, Swasthya Bhawan \\ Sector-V, Salt Lake, Kolkata, West Bengal, India 700091 \\ *gdipa01@gmail.com
}

\begin{abstract}
The emergence of a new Coronavirus Disease 2019-2022 has turned the globe down and disrupted main determinants of health. The world constitutes by more than 2.2 billion children, which is approximately $28 \%$ of the world's population. Compare to adult, this pandemic has a long -term adverse consequences among children and adolescents. The objective of this literature review was to examine the impact of COVID-19 pandemic on children and adolescent's mental health. PubMed and Google Scholar databases were searched from 07 April 2021 to 22 April 2021. A systematic literature search was performed in accordance with PRISMA and 07 literatures were selected. Among 16,169 samples, the mean percentage of male was higher 5 by $6.11 \%$ than female of $43.89 \%$. Depression was mentioned in three studies and the percentages were $43.7 \%(n=8079), 22.6 \%(n=2330)$, and $22.8 \%(n=3613)$. Anxiety was mentioned in four studies and the percentages were $37.4 \%(n=8079), 18.9 \%(n=2330)$, and $23.87 \pm 15.79$ and $29.27 \pm 19.79$ $(n=3613)$ and in one study according to CAQ and NRS, the level of anxiety was $19.4 \%$ and $21.8 \%$. The combination of anxiety and depression was $31.3 \%$. One study mentioned that pro social behaviour score was higher in females than males. In other two studies, various psychological symptoms are mentioned such as worry, fear, helplessness, boredom, difficulty in concentration, irritability, restlessness, nervousness, feeling of loneliness and uneasiness. These psychological symptoms have long-term effect on child's health. Therefore, as a nurse, we should take care of the child and aware that the child and their parents regarding various psychological problems and its management.
\end{abstract}

Keywords: adolescent; children; COVID-19; mental or psychological health; pandemic

\begin{tabular}{|c|c|c|}
\hline $\begin{array}{l}\text { First Received } \\
18 \text { April } 2021\end{array}$ & $\begin{array}{c}\text { Revised } \\
20 \text { April } 2020\end{array}$ & $\begin{array}{c}\text { Accepted } \\
24 \text { April } 2021\end{array}$ \\
\hline $\begin{array}{c}\text { Final Proof Received } \\
28 \text { June } 2021\end{array}$ & & $\begin{array}{l}\text { Published } \\
\text { 05 July } 2021\end{array}$ \\
\hline $\begin{array}{l}\text { How to cite (in APA style) } \\
\text { Ghosh, D. (2021). The Impact of the Covid-19 } \\
\text { Literature Review. Indonesian Journal } \\
\text { https://doi.org/10.37287/ijghr.v3i3.483 }\end{array}$ & $\begin{array}{l}9 \text { Pandemic on Children anc } \\
\text { of Global Health }\end{array}$ & $\begin{array}{l}\text { d Adolescents Mental Health: A } \\
\text { Research, 3(3), 281-288. }\end{array}$ \\
\hline
\end{tabular}

\section{INTRODUCTION}

The emergence of a new Coronavirus Disease,2019-2022, has turned the globe down and disrupted main determinants of health(Zemrani et al., 2021). The world constitutes by more than 2.2 billion children, which is approximately $28 \%$ of the world's population. According to UNICEF $16 \%$ of the world's population is between 10 to 19 (UNICEF, 2019). Recent study results have suggested that children are suffered by milder symptoms. $45 \%$ typical symptoms, and $42 \%$ with mild respiratory symptoms were presented in COVID positive children. Whereas, $13 \%$ were asymptomatic, no child presented with life-threatening symptoms (Saleem et al., 2020).COVID-19 has a great impact on the lives of people around the world, children and adolescents also included. Compare to adult, this pandemic have an long term adverse consequences among children and adolescents mental health(Singh et al., 2020). 
People experienced forced to maintain social isolation, social distancing and staying at home during the lockdown and quarantine period. The results due to this situation,children are faced psychological distress and depressive mood. In addition, when the number of positive cases and deaths areincreased, it had a bad impact on children and adolescents mental health such as fear of fell ill(Deolmi \& Pisani, 2020).

Due to this pandemic quarantine situation, schools were closed, which had a significant change in daily activity and routinework for students. The consequence of school closure is psychological traumatic effectamong students. Children missed their schoolbased physical activities which leads to increased obesity among children. The cancellation of sports and activity classes leads to addicted in Zoom, YouTube, Instagram, and proprietary mobile applications. The studies report present that there are several adverse effects on psychological wellbeing such as anxiety, worrying, irritability, depressive symptoms and even posttraumatic stress disorder symptoms in $18.9 \%$ to $43.7 \%$ among children in Asian, European or American countries(Cusinato et al., 2020).

This review of the scientific literature about the impactof COVID-19 pandemic in children and adolescents' mental health due to isolation, movement restriction, social distancing The objectives of this literature review was to examine the impact ofCOVID-19 pandemic on children and adolescent's mental health.

\section{METHOD}

A systematic literature search was performed in accordance with PRISMA (Preferred Reporting Items for Systematic Reviews and Meta Analyses). Published studies were found using a thorough search strategy of the PubMed and Google Scholar databases from 07 April 2021 to 22 April 2021. Review literature regarding impact on mental health during COVID19 pandemic by using the keywords "COVID-19", "coronavirus", "pandemic", "mental health", "adolescent", "child", "children", "pediatric". References of the articles also were reviewed and the corresponding abstracts and full articles were reviewed and accessed if relevant. For this literature review, specific focus was given on impact of COVID 19 on children and adolescent'smental health. The reviewer selects only articles with English language. There was no restriction for regional articles and the date of publication. The target population for this review was up to18 years. There wereno limitations related to gender, race or health condition. Reviewer excluded the articles with data of adults and general population, repeat data points due to updates,systematic reviews, narrative reviews, brief commentaries, and editorial communicationsfrom this review. Articles about coronavirus in the general population were also excluded. According inclusion and exclusion criteria 07articles are included for this systematic review.

The information that was extracted were as follows: study data (author, year, geographic area, study age group, study title), demographics data (including age and gender, age range), data related to psychological or mental health(anxiety, depression, sleep problem etc.) and result and conclusion from review articles. After a primary search, total of 117 publications were reviewed. After primary review, 8 articles were removed due to duplication. The remaining 109 eligible papers were reviewed initially and then97 irrelevant articles were excluded (PRISMA flow chart: Fig. 1) and only 11eligible articles were selected for full text review. Ultimately, 7 articles were included in the final review, including 16,169 participants. The selected studies are presented in table-1. 


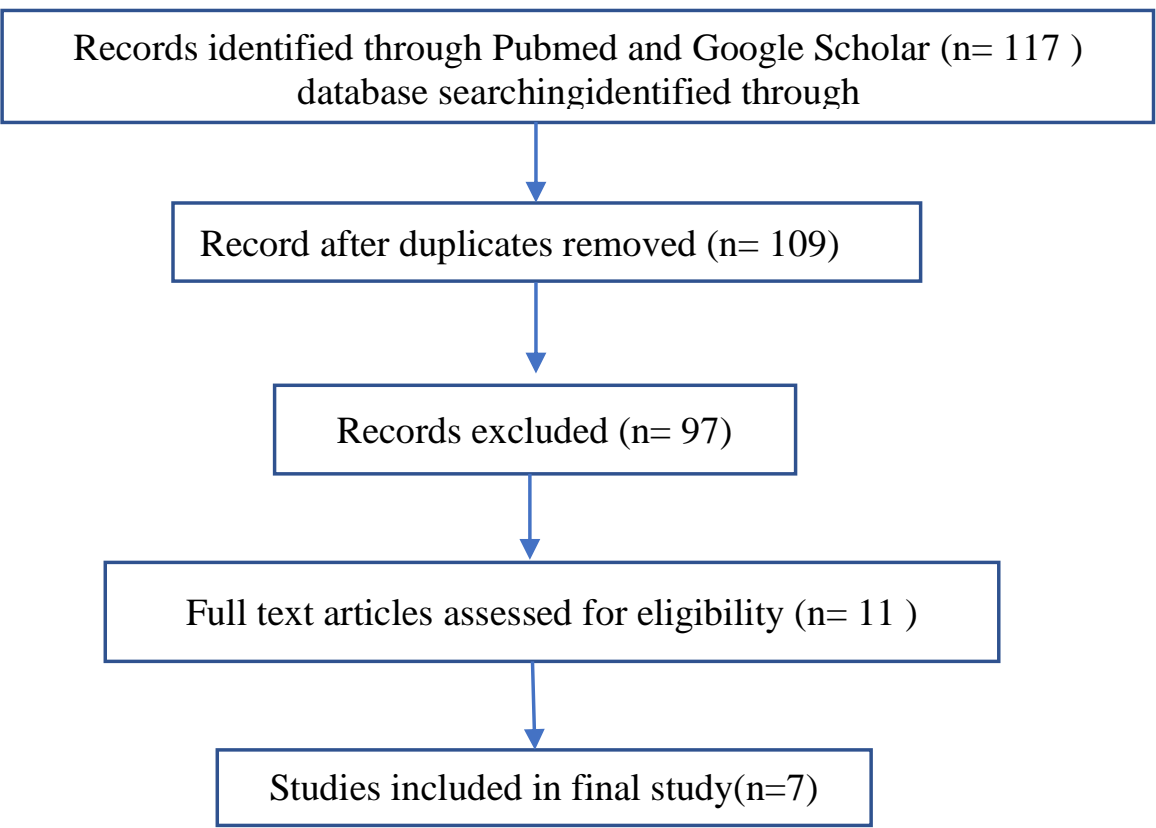

Fig. 1 Search Strategy using PRISMA flowchart

Table 1.

Articles Included in Systematic Review

$\begin{array}{ccc}\text { Articles } & \text { Study Title } & \text { Study Country } \\ \text { Reference) } & & \end{array}$

\begin{tabular}{|c|c|c|}
\hline $\begin{array}{l}(\text { Saurabh \& } \\
\text { Ranjan, 2020) }\end{array}$ & $\begin{array}{l}\text { Compliance and Psychological Impact of Quarantine in } \\
\text { Children and Adolescents due to Covid-19 Pandemic }\end{array}$ & India \\
\hline $\begin{array}{l}\text { (Jiang et al., } \\
2020)\end{array}$ & $\begin{array}{l}\text { Prevalence and socio-demographic correlates of } \\
\text { psychological health problems in Chinese adolescents } \\
\text { during the outbreak of COVID-19 } \\
\text { Shuang-Jiang }\end{array}$ & China \\
\hline $\begin{array}{l}\text { (Data \& } \\
\text { Racial, 2020) }\end{array}$ & $\begin{array}{l}\text { Mental Health Status Among Children in Home } \\
\text { Confinement During the Coronavirus Disease } 2019 \\
\text { Outbreak in Hubei Province, China }\end{array}$ & China \\
\hline $\begin{array}{l}\text { (Cusinato et } \\
\text { al., 2020) }\end{array}$ & $\begin{array}{l}\text { Stress, Resilience, and Well-Being in Italian Children } \\
\text { and Their Parents during the COVID-19 Pandemic }\end{array}$ & Italy \\
\hline $\begin{array}{l}\text { (Duan et al., } \\
\text { 2020) }\end{array}$ & $\begin{array}{l}\text { An investigation of mental health status of children and } \\
\text { adolescents in china during the outbreak of COVID-19 }\end{array}$ & China \\
\hline $\begin{array}{l}\text { (Andr et al., } \\
\text { n.d.) }\end{array}$ & $\begin{array}{l}\text { Children's Anxiety and Factors Related to the COVID- } \\
19 \text { Pandemic: An Exploratory Study Using the } \\
\text { Children's Anxiety Questionnaire and the Numerical } \\
\text { Rating Scale }\end{array}$ & Brazil \\
\hline $\begin{array}{l}\text { (Orgilés et al., } \\
2020) \text {. }\end{array}$ & $\begin{array}{l}\text { Immediate Psychological Effects of the COVID-19 } \\
\text { Quarantine in Youth From Italy and Spain }\end{array}$ & and Spain \\
\hline
\end{tabular}


Table 2.

Demographic Detail of Systematic Literature Review

\begin{tabular}{ccccc}
\hline $\begin{array}{c}\text { Articles } \\
\text { (Reference) }\end{array}$ & N of studies & Male $\mathrm{n}=(\%)$ & $\begin{array}{c}\text { Female } \\
\mathrm{n}=(\%)\end{array}$ & $\begin{array}{c}\text { Age } \\
\text { range(years })\end{array}$ \\
\hline $\begin{array}{c}\text { (Saurabh \& } \\
\text { Ranjan, 2020) }\end{array}$ & $\begin{array}{c}\text { (Quarantined } \mathrm{n}=121 \& \text { \& } \\
\text { Non- quarantined } \mathrm{n}=131)\end{array}$ & 85.12 & 14.88 & $9-18$ \\
\hline $\begin{array}{c}\text { (Jiang et al., } \\
\text { 2020) }\end{array}$ & 8079 & 46.5 & 53.5 & $12-18$ \\
\hline $\begin{array}{c}\text { (Data \& Racial, } \\
\text { 2020) }\end{array}$ & 2330 & 56.7 & 43.3 & Grade 2-6 \\
\hline $\begin{array}{c}\text { (Cusinato et } \\
\text { al., 2020) }\end{array}$ & 463 & 56.2 & 43.8 & $5-17$ \\
\hline $\begin{array}{c}\text { (Duan et al., } \\
\text { 2020) }\end{array}$ & $\begin{array}{c}\text { (359 children and 3254 } \\
\text { adolescents) }\end{array}$ & 50.15 & 49.85 & $7-18$ \\
\hline $\begin{array}{c}\text { (Andr et al., } \\
\text { n.d.) }\end{array}$ & 289 & 45.6 & 54.4 & $6-12$ \\
\hline $\begin{array}{c}\text { (Orgilés et al., } \\
\text { 2020) }\end{array}$ & 1,143 & 52.5 & 47.5 & $3-18$ \\
\hline
\end{tabular}

\section{RESULTS}

\section{Demographics data}

7 studies were selected for this systematic review. The sample size was 16,169 children and adolescents (Table 2). Age range of this study 3-18 years. For one study grade 2-6 was mentioned. The mean percentage of male and female student are $56.11 \%$ and $43.89 \%$.

\section{Summary of selected studies}

A study was conducted oncompliance and psychological Impact of quarantine in children and adolescents due to Covid-19 Pandemic in India.The study sample was quarantined 121 children and adolescents and their parents. As a control group non- quarantined 131 children and adolescents and their parents were taken. The researcher was taking interview regarding the compliance and psychological distress during the quarantine period. The study result showed that,greater psychological distress in quarantined children and adolescents than nonquarantined children and adolescents $(\mathrm{p}<0.001)$. The study result present that, the percentage of worry, fear and helplessness of quarantined children and adolescents were $(68.59 \%)$, $(61.98 \%)$ and $(66.11 \%)$ (Saurabh \& Ranjan, 2020).

A study was conducted on prevalence and socio-demographic correlates of psychological health problems during the outbreak of COVID-19among adolescents in China. The study sample was 8079 students. Online survey was done for data collection.The Patient Health Questionnaire (PHQ-9) and the Generalized Anxiety Disorder (GAD-7) questionnaire were used for this study. The study result showed that, Chinese high school students were faced depression (43.7\%), anxiety (37.4\%), and a combination of depression and anxiety $(31.3 \%)$ during thepandemic situation. Female gender was the higher risk factor for depressive and anxiety symptoms as per multivariable logistic regression analysis and the senior high school students had the greater prevalence of depressive and anxiety symptoms in terms of grades(Jiang et al., 2020). 
A study was conducted on mental health status among children in home confinement during the Coronavirus disease 2019 outbreak in Hubei Provinc (Data \& Racial, 2020)e. The study result showed that, students reported depressive symptoms $22.6 \%$, which was higher than other investigations in primary schools of China (17.2\%). During the outbreak of COVID19 ,children's depressive symptoms were increased due to reduction of outdoor activities and social interaction. The study found that students reported anxiety symptoms $18.9 \%$, which is higher than the prevalence in other surveys.

A study was performed on stress, resilience, and wellbeing in Italian Children and Their Parents during the COVID-19 Pandemic(Cusinato et al., 2020). The study sample was 463 Italian parents along with their children aged 5-17. Psychological General Well Being Index (PGWB) and Strengths and Difficulties Questionnaire (SDQ) were used to assess the parental and children's well-being through an online survey. The study result of the independent sample t-test revealed that the children's gender only significantly affected the prosocial behaviour scale ( $\mathrm{t} 455=-4.12, \mathrm{p}<0.001)$, and females scores was higher than males (Mboys $=7.26, \mathrm{SE}=0.117 ;$ Mgirls $=7.94, \mathrm{SE}=0.116)$. The study present, negative correlations with all SDQ scales (values ranging from $r=-0.40$ to $r=-0.63$ ), only exceptional for the prosocial behaviour scale $(r=0.43)$. The study results conclude that due to changes in daily routine parents' psychological dimensions werenegatively affectedand also exposing children's wellbeing also affected.

A study was conducted on an investigation of mental health status of children and adolescents during the outbreak of COVID-19 in China(Duan et al., 2020).For this study,online convenience sampling method, questionnaires, such as Spence Child Anxiety Scale, Child Depression Inventory and Coping style Scale, were usedamong 359 children and 3254 adolescents. The study result showed that, anxiety levels of children and adolescents were $23.87 \pm 15.79$ and $29.27 \pm 19.79$. The percentage of depressive symptoms among children and adolescents was $22.28 \%$.

An exploratory study was conducted on children's anxiety and factors related to the COVID19 pandemic among 289 children in Brazil (Andr et al., n.d.).The Children's Anxiety Questionnaire and the Numerical Rating Scale were used to measure anxiety level among 612 years and their guardians. 157 girls and 132 boys were enrolled for this study, with a mean age of $8.84( \pm 2.05)$ years. Based on CAQ, the prevalence of anxiety was $19.4 \%$, Based on NRS, the prevalence of anxiety was $21.8 \%$.

A study was conducted onimmediate psychological effectquarantine in youth due to COVID19 in Italy and Spain(Orgilés et al., 2020). The sample size was 1143. Sample was collected by survey from parents of Italian and Spanish children whose children's age were from 3 to 18 years. The researcher collected information about how the quarantine affects their children and themselves, compared to before the home confinement. The study result showed that due tothe quarantine,children's emotional state and behaviours were changed according to $85.7 \%$ parents.According to parents, the study result found that, the most frequent symptoms were difficultin concentration $76.6 \%$, and the next was boredom $52 \%$. Other psychological effects were irritability $39 \%$, restlessness $38.8 \%$, nervousness $38 \%$, feelings of loneliness $31.3 \%$, uneasiness $30.4 \%$, and worries $30.1 \%$. Italians' parents reported less symptoms than Spanish.

\section{DISCUSSION}

Pandemic, such as COVID-19, have adverse effect on children and adolescents physical, menta, educational, social and nutritional health due to the risk of illness, protective 
confinement, social isolation, school closure, fall down of family income. COVID-19 has also increased stress level among parents and caregivers, which has also affected children and adolescent's mental health. In this literature review, 07 articles were taken for review according to PRISMA flowchart. Out of 07 literature review, 03 studies from China, 01 from India, 01 from Brazil, 01 study from Italy, and 01 study from both Italy and Spain. Among 16,169 children and adolescent, the mean percentage of male is higher $56.11 \%$ than female $43.89 \%$. Out of 07 studies, in one study the age of students was not mentioned, the study was done according to grade of students like Grade 2-6. The lowest mentioned age of child is 3 and the highest mentioned age is 18 .

From above literature review, depression was mentioned in three studies and the percentages are $43.7 \% \%(\mathrm{n}=8079), 22.6 \%(\mathrm{n}=2330)$ and $22.8 \%(\mathrm{n}=3613)$. Anxiety was mentioned in four studies and the percentages are $37.4 \%(\mathrm{n}=8079), 18.9 \%(\mathrm{n}=2330)$ and $23.87 \pm 15.79$ and 29.27 $\pm 19.79(\mathrm{n}=3613)$ and in one study according to CAQ and NRS the level of anxiety was $19.4 \%$ and $21.8 \%$. The combination of anxiety and depression $31.3 \%$ is mentioned in one study. In one study mentioned that, prosocial behaviour score is higher in females than males. In other two studies, various psychological symptoms are mentioned like worry, fear, helplessness, boredom, difficulty in concentration, irritability, restlessness, nervousness, feeling of loneliness and uneasiness due to COVID-19 pandemic.

This study supported by a literature review psychological and psychiatric impact of COVID19 pandemic among children and adolescent (Deolmi \& Pisani, 2020). The study result revealed that, due to the pandemic situation, social isolation and parenteral stress, children and adolescents are more prone to develop anxiety and depressive symptoms. There is higher risk of developing psychiatric symptoms in high grade students, females and low-income families.

\section{Limitation}

Only one reviewer reviewed all the articles, the reviewed literature is only 07 , the quality of literatures also not measured. Statistical calculations was not performed and publication bias was also not checked.

\section{CONCLUSION}

So, Covid-19 pandemic hasa significant impact on psychological or mental health in children and adolescents. The prevalence of depression, anxiety and other psychological symptoms like worry, fear, helplessness, boredom, difficulty in concentration, irritability, restlessness, nervousness, feeling of loneliness and uneasiness are found among them. These psychological symptoms have long term effect on child's health. So, as a nurse, we should take care of the child and society and aware the child and their parents regarding various psychological problems and its management.

\section{REFERENCES}

Zemrani, B., Gehri, M., Masserey, E., Knob, C., \& Pellaton, R. (2021). A hidden side of the COVID-19 pandemic in children: the double burden of undernutrition and overnutrition. International Journal for Equity in Health, 20(1), 1-4. https://doi.org/10.1186/s12939-

Saleem, H., Rahman, J., Aslam, N., Murtazaliev, S., \& Khan, S. (2020). Coronavirus Disease 2019 (COVID-19) in Children: Vulnerable or Spared? A Systematic Review. Cureus, 2019(5). https://doi.org/10.7759/cureus.8207

Singh, S., Roy, D., Sinha, K., Parveen, S., Sharma, G., \& Joshi, G. (2020). Since January 
2020 Elsevier has created a COVID-19 resource centre with free information in English and Mandarin on the novel coronavirus COVID- 19. The COVID-19 resource centre is hosted on Elsevier Connect, the company' s public news and information. Psychiatry Research, 293(January).

Cusinato, M., Iannattone, S., Spoto, A., Poli, M., Moretti, C., Gatta, M., \& Miscioscia, M. (2020). Stress, resilience, and well-being in Italian children and their parents during the COVID-19 pandemic. International Journal of Environmental Research and Public Health, 17(22), 1-17. https://doi.org/10.3390/ijerph17228297

Saurabh, K., \& Ranjan, S. (2020). Compliance and Psychological Impact of Quarantine in Children and Adolescents due to Covid-19 Pandemic. Indian Journal of Pediatrics, 87(7), 532-536. https://doi.org/10.1007/s12098-020-03347-3

Jiang, S., Li, Z., Zhang, G., Lei, L., Zhao, W., Guo, C., Qi, J., Jin, W., \& Chen, C. (2020). Prevalence and socio - demographic correlates of psychological health problems in Chinese adolescents during the outbreak of COVID - 19. European Child \& Adolescent Psychiatry. https://doi.org/10.1007/s00787-020-01541-4

Data, N., \& Racial, J. M. (2020). Mental Health Status Among Children in Home Confinement During the Coronavirus Disease 2019 Outbreak in Hubei Province , China. 2020-2022. https://doi.org/10.1353/dem.2008.0004

Duan, L., Shao, X., Wang, Y., Huang, Y., Miao, J., \& Yang, X. (2020). Since January 2020 Elsevier has created a COVID-19 resource centre with free information in English and Mandarin on the novel coronavirus COVID- 19. January.

Andr, M., Avila, G. De, Tadao, P., Filho, H., Let, F., Souza, R., Berghammer, M., Nolbris, M. J., Olaya-contreras, P., \& Nilsson, S. (n.d.). Children' s Anxiety and Factors Related to the COVID-19 Pandemic: An Exploratory Study Using the Children's Anxiety Questionnaire and the Numerical Rating Scale. 1-13.

Orgilés, M., Morales, A., Delvecchio, E., Mazzeschi, C., Espada, J. P., \& Marzocchi, G. M. (2020). Immediate Psychological Effects of the COVID-19 Quarantine in Youth From Italy and Spain. 11(November), 1-10. https://doi.org/10.3389/fpsyg.2020.579038

Deolmi, M., \& Pisani, F. (2020). Psychological and psychiatric impact of COVID-19 pandemic among children and adolescents. Acta Biomedica, 91(4), 1-5. https://doi.org/10.23750/abm.v91i4.10870 
Indonesian Journal of Global Health Research, Vol 3 No 3, August 2021, pp. 281-288 